\title{
Biomedical Applications of Diamond-Like Carbon Coatings: A Review
}

\author{
Ritwik Kumar Roy, Kwang-Ryeol Lee \\ Future Technology Research Division, Korea Institute of Science and Technology, P.O. Box 131, Cheongryang, \\ Seoul 130-650, Korea
}

Received 16 May 2006; revised 15 November 2006; accepted 27 November 2006

Published online 6 February 2007 in Wiley InterScience (www.interscience.wiley.com). DOI: 10.1002/jbm.b.30768

\begin{abstract}
Owing to its superior tribological and mechanical properties with corrosion resistance, biocompatibility, and hemocompatibility, diamond-like carbon (DLC) has emerged as a promising material for biomedical applications. DLC films with various atomic bond structures and compositions are finding places in orthopedic, cardiovascular, and dental applications. Cells grew on to DLC coating without any cytotoxity and inflammation. DLC coatings in orthopedic applications reduced wear, corrosion, and debris formation. DLC coating also reduced thrombogenicity by minimizing the platelet adhesion and activation. However, some contradictory results (Airoldi et al., Am J Cardiol 2004;93:474-477, Taeger et al., Mat-wiss u Werkstofftech 2003;34:1094-1100) were also reported that no significant improvement was observed in the performance of DLC-coated stainless stent or DLC-coated femoral head. This controversy should be discussed based on the detailed information of the coating such as atomic bond structure, composition, and/or electronic structure. In addition, instability of the DLC coating caused by its high level of residual stress and poor adhesion in aqueous environment should be carefully considered. Further in vitro and in vivo studies are thus required to confirm its use for medical devices. (C) 2007 Wiley Periodicals, Inc. J Biomed Mater Res Part B: Appl Biomater 83B: 72-84, 2007
\end{abstract}

Keywords: carbon; hemocompatibility; joint replacement; stent; DLC; biomaterials

\section{INTRODUCTION}

The fate of a biomaterial is determined by its reaction with the biological environment. ${ }^{1}$ The human body is so sensitive and hostile that the properties of the biomaterial should be compatible enough as not to disturb the various functions of human body. Biomaterials should be chemically and biologically inert to the surrounding cells and body fluids. It should also be hard and wear resistant with a low coefficient of friction for some applications. In addition to corrosion resistance, it should not release toxic and carcinogenic elements into the human body. It would be more desirable if the biomaterials have functions to provide a biomedical treatment.

The common metals that have been used for different biomedical applications are titanium, 316 stainless steel, titanium oxide, titanium nitride, cobalt-chromium alloy, and nitinol alloys. ${ }^{2,3}$ These materials suffer from drawbacks in case of sustained and long-term use like cytotoxicity, release of metal ions, corrosion, and wear. For example,

Correspondence to: K.-R. Lee (e-mail: krlee@kist.re.kr)

Contract grant sponsor: Center for Nanostructured Materials Technology, Ministry of Science and Technology, Korea; Contract grant number: 05K1501-01610

(C) 2007 Wiley Periodicals, Inc. though stainless steel has been successfully used in many biomedical applications, it can become corroded and releases $\mathrm{Cr}, \mathrm{Ni}, \mathrm{Mn}$, and $\mathrm{Mo}$ ions when the metal is placed in coronary vessels. ${ }^{4}$ Because the metal ions and other particles released from implants are suspected to trigger allergic reactions, as in the case of $\mathrm{Ni}$, or to cause tumors, ${ }^{5}$ there is growing interest searching for less corrosive and inert biomaterials for their wide use in clinical applications. Previously, medical devices were selected based on its material and bulk properties. However, it is now recognized that the surface properties of the device mainly govern its biomedical applications. In most cases, a surface modification is considered to be a prerequisite for better biocompatibility. Ion beam processing or coating the medical devices with inert, corrosion resistant, adhesive, and biocompatible materials have been gaining importance from last decade. ${ }^{6}$

Diamond-like carbon (DLC) has emerged as a potential material in recent years due to its high hardness, low frictional coefficient, high wear and corrosion resistance, chemical inertness, high electrical resistivity, infrared-transparency, high refractive index, and excellent smoothness. All these properties match well with the criteria of a good biomaterial for applications in orthopedic, cardiovascular, contact lenses, or dentistry. DLC film comprises a mixture of $\mathrm{sp}^{2}$ and $\mathrm{sp}^{3}$ carbon bonds and is deposited by using high 
energy carbon species. DLC films are produced by a number of techniques like ion beam deposition, ${ }^{7}$ radio frequency plasma enhanced chemical vapor deposition (r.f.-PECVD), ${ }^{8}$ filtered cathodic vacuum arc (FCVA), ${ }^{9}$ ion plating, ${ }^{10}$ plasma immersion ion implantation and deposition (PIIID), ${ }^{11} \mathrm{mag}$ netron sputtering, ${ }^{12}$ ion beam sputtering, ${ }^{13}$ pulsed laser deposition, $^{14}$ and mass selected ion beam deposition. ${ }^{15}$ The hydrogen content in DLC films varies up to $40 \%$. Because of its amorphous structure, DLC films can be easily doped and alloyed with different elements. This leads to a wide range of properties depending on its $\mathrm{sp}^{3}, \mathrm{sp}^{2}$, and hydrogen content together with element incorporation.

Debakey ${ }^{16}$ used the first carbon-based biomaterials for prosthetic aortic valves. The biocompatibility of DLC was investigated in the early $90 \mathrm{~s}^{17-19}$ through cell culture techniques and observing biotolerance after implanting in laboratory animals. Later on studies exposed DLC coatings to human fibroblast and human osteoblast-like cells for several days. $^{20,21}$ DLC coatings also showed promising results as a hemocompatible material. ${ }^{22-25}$ Several other studies have been performed to test the possibility of DLC as a biocompatible material. ${ }^{26-28}$ These investigations indicated that DLC may be an alternative to current materials for biomedical applications. The medical implants for orthopedic and cardiovascular applications are subject to severe external forces during the implants lifetime in the body environment, which sometimes leads to delamination and spallation of the coatings. To get rid of this problem, several attempts were made to incorporate certain elements into the surfaces of biomaterials or use an interlayer which improves its adhesive properties, corrosive resistance, and biocompatibility. To attain superior biocompatible properties adapted for a specific biological function, DLC films have been successfully doped and alloyed with elements like $\mathrm{Si}, \mathrm{P}, \mathrm{Ti}$, $\mathrm{N}, \mathrm{F}, \mathrm{Cu},{ }^{29-34}$ and compounds like Ca-O. ${ }^{35}$

However, serious controversy remains in the effect of the DLC coating for biomedical applications. For example, clinical tests of DLC-coated vascular stents revealed that the DLC coating does not provide significant improvements in restenosis rate over uncoated stents. ${ }^{36}$ This result would be hardly understood if one considers the excellent hemocompatibility of DLC coating as reported in most in vitro or in vivo tests. Ten-year follow-up of DLC-coated artificial hip joints showed that failure rate of the DLC-coated Ti-6Al-4V femoral head is much higher than alumina femoral head. ${ }^{37}$ Because the negative results of the clinical test significantly affect the biomedical applications of the DLC coating, the reason for the failures in clinical tests should be carefully investigated in view of materials science. It is yet to be evident that the failures are caused by the inherent characteristics of the DLC film or the delamination of DLC coating during service.

In the present article, we reviewed the present status of the research for biomedical applications of DLC coating. It must be noted that DLC is not a specific material but a group of materials with a wide range of atomic bond structure and properties depending on the preparation method. ${ }^{38}$
Without scientific classification of the DLC coatings, most in vitro and in vivo test of DLC-coated biomaterials might cause confusion on the effect of the DLC coating. We thus focused on the aspect of materials structure in discussing the biomedical properties of the DLC coating. In this review paper, "diamond-like carbon (DLC)" will be used as a general term of this group of amorphous carbon film. "Hydrogenated amorphous carbon (a-C:H)," "tetrahedral amorphous carbon (ta-C)," or "nonhydrogenated amorphous carbon (a-C)" will be used to specify the structure of the film. In this respect, the present review can be considered as an extended discussion of the previous reviews on this issue. $^{33,34,39-41}$

\section{BIOCOMPATIBILITY OF DLC COATINGS}

The biocompatibility of a material is determined by some in vitro and in vivo tests, involving the interaction of the material with biological cells. The cell that plays a dominant role in inflammation and interaction with implanted materials is the macrophage, which is an important cell to test the biocompatibility of a material. Lactate dehydrogenase (LDH), an enzyme released at cell death, is used as a measure of cell viability. For effective contact and growth on the implant, the cells should spread and attach well on the implant surface. It has been observed that a glycoprotein, fibronectin, mediates and promotes the spreading and adhesion of cells on biomaterials. ${ }^{42}$ The cells of monocytic lineage generally interact with the DLC-coated implants and cause various inflammatory reactions. Hence, by investigating the activation of human monocytes and macrophages on the biomaterials, the biocompatibility could be estimated.

Hydrogenated amorphous carbon (a-C:H) films are most widely investigated among DLC films in the previous works on the biocompatibility. In the early $90 \mathrm{~s}$, some attempts were done to investigate the biocompatibility of a-C:H films prepared by ion beam deposition method using a saddle field ion source. ${ }^{17,18}$ On growing mouse peritoneal macrophages and mouse fibroblast on tissue culture plates treated with a-C:H, no toxicological effects on the cells in culture was observed. It was noticed that cells grew on a-C:H film without any inflammation. ${ }^{18}$ Mouse fibroblast and peritoneal macrophages were exposed to the a-C:H films for a week and no damage to the cells was observed. On performing the cytotoxicity tests using a standard cell line, it was found out that the a-C:H films, prepared by radio frequency (r.f.) glow discharge of methane and hydrogen gas mixture, promotes cell attachment and normal cell growth rates. $^{43}$ In vitro studies of biocompatibility of a-C:H coatings, produced by r.f.-PECVD using butane, with $\mathrm{Si}$ intermediate layer, were carried out by Butter et al. $^{20}$ They grew mouse macrophages, human fibroblast, and human osteoblast-like cells on the samples up to 3 days and found no cytotoxic effect after carrying out LDH assays at 24,48 , and $72 \mathrm{~h}$. Several other studies were 
made on the morphological behavior of fibroblast and osteoblast cells on hydrogenated carbon nitride coating prepared by ion beam assisted sputtering method or on a-C:H coating by r.f.-PECVD method, which revealed good surface biocompatibility of the coatings. ${ }^{21,44}$

Schroeder et al. ${ }^{32}$ performed bone marrow cell culture tests on Ti-incorporated amorphous hydrogenated carbon films, prepared by using a hybrid process of RF plasma and magnetron sputtering, to observe its effects on cellular reaction, osteoblast, and osteoclast activity. Ti addition to the a-C:H films resulted in increased bone cell proliferation and minimized activity of osteoclast-like cell. DornerReisel et al. $^{35}$ noted that the incorporation of $\mathrm{CaO}$ in a-C:H coatings, formed by the plasma decomposition of gaseous carbon precursors, improved the biological acceptance by L929 mouse fibroblast cells. The adhesion, activation, and cytoskeletal architecture of primary human monocytes and macrophages on a-C:H film prepared by r.f.-PECVD were studied by Linder et al. using immunofluorescence. ${ }^{26}$ Their investigations indicated that a-C:H coatings were biocompatible to the human monocytes and macrophages. An attempt was made to study the biocompatibility of inductively coupled plasma assisted chemical vapor deposited a-C:H in chronic neuroprosthetic implants by exposing the samples to glial and fibroblast cells in vitro and promising results were obtained. ${ }^{45}$ All these in vitro studies showed that a-C:H films tended to promote the growth and adhesion of cells without any toxilogical effect.

There are other applications where it is desirable that there should not be any cell attachment to a surface, for example, in case of catheters and temporary implants. It has been observed that the addition of toxic elements $\mathrm{Cu}$ or $\mathrm{V}$ to DLC films inhibit the growth and spreading of cells on the DLC surfaces. ${ }^{46}$

After getting a primary indication of the biocompatibility of DLC films through in vitro tests, several in vivo studies were started by placing DLC-coated implants in laboratory animals. An attempt was made to study the tissue response of a-C:H-coated Ti by implanting the samples in skeletal muscles of rabbit for 1 year. ${ }^{27}$ The study did not reveal any delamination of the film in the skeletal muscles and indicates its biocompatible nature. A long term investigation was carried out on a-C:H-coated orthopedic pins and screws by implanting in guinea pig for 52 weeks. ${ }^{19}$ The film was deposited by dense r.f.-PECVD using methane. It was observed that on implantation, thin connective tissue capsules were built from fibrocytes and collagen fibers in subcutaneous tissue, bones and muscles are formed, but no phagocytic reaction and corrosion products in the walls of the capsule was noticed. After implanting r.f. plasma-enhanced chemical vapor deposited a-C:Hcoated $\mathrm{CoCr}$ cylinder in transcortical sites of sheep and intramuscular location of rats for 3 months, it has been observed that the DLC-coated implants did not show any significant toxicological effect and are well tolerated in both the sheep and rat body. ${ }^{47}$ A comparative study was made by implanting $\mathrm{Zr}$, Ti, $\mathrm{Al}$, and DLC-coated $\mathrm{Zr}$ in the tibiae of Wilster rats for 30 days. ${ }^{48}$ After investigating the tissue-implant interface it was noted that $\mathrm{Zr}$ and DLCcoated $\mathrm{Zr}$ indicated better tissue response than the other metals. DLC-coated steel was implanted inside fractured bone in the human body for 7 months and no corrosion, metal release or inflammation was observed. ${ }^{49}$ However, detailed information about the structure and composition of DLC films in Refs. 48, 49 is not available. All these studies indicate that DLC coatings are quite biocompatible and are not inducing any inflammatory reaction inside animal bodies. However, more in-vivo studies are required to ascertain the correct performance and operation of DLC-coated implants.

The above in vitro and in vivo studies indicated the biocompatibility of DLC films prepared by a variety of techniques. However, the proper dependence of its biocompatibility on its surface chemistry, atomic bond structure, $\mathrm{H}$ content, and dopant is not fully understood. It has been observed that the protein fibronectin governs the adhesion and spreading of cells on a material surface. ${ }^{50}$ The glycoprotein fibronectin consists of multiple specific binding sites and is capable of interacting with a wide variety of other biomaterials, through the formation of fibrilar extracellular matrix or fibrils. So, the specific surface of a biomaterial plays a key role in adsorption of fibronectin and hence better proliferation of cells. Some studies revealed that the adhesion and spreading of cells on DLC surfaces is related to the bonding structure present on the surface and the ratio of $\mathrm{sp}^{2} / \mathrm{sp}^{3}$ (as described in Ref. 39). It has also been observed that the microstructure of the DLC films and the kind of dopant seemed to influences the biocompatibility of the films. ${ }^{33}$ A recent study showed that nitrogen doped a-C:H prepared by PIIID improved the cell adhesion by $10 \%$ more than the undoped one and the cell adhesion was maximized for a N:C ratio of $0.2 .^{51}$ This improvement in cell adhesion was explained due to the presence of $\mathrm{C}-\mathrm{N}$ and $\mathrm{N}-\mathrm{H}$ bonds which seemed to promote the adsorption of proteins on the film surface. All these investigations revealed the prospects of DLC as a biocompatible material, which provoked growing interest in DLC-coated implants for orthopedics, cardiovascular, and dental applications.

\section{ORTHOPEDIC APPLICATIONS}

The inertness, corrosion and wear resistance, high hardness, low frictional coefficient, and biocompatibility of DLC films have attracted interest regarding its use as a biomaterial in orthopedic applications. The main problem with the prosthetic joints lies in its wear and corrosion during longterm use. The debris formed as a consequence of this wear results in tissue inflammation, osteolysis, and finally loosening of the implants. When two material surfaces slide against each other and are in relative motion, the material having lower hardness is worn out. The material will also come in contact with human body fluids. So in prosthetic joints, the coating material should be hard and inert enough to prevent the wear out and corrosion. The coating material 


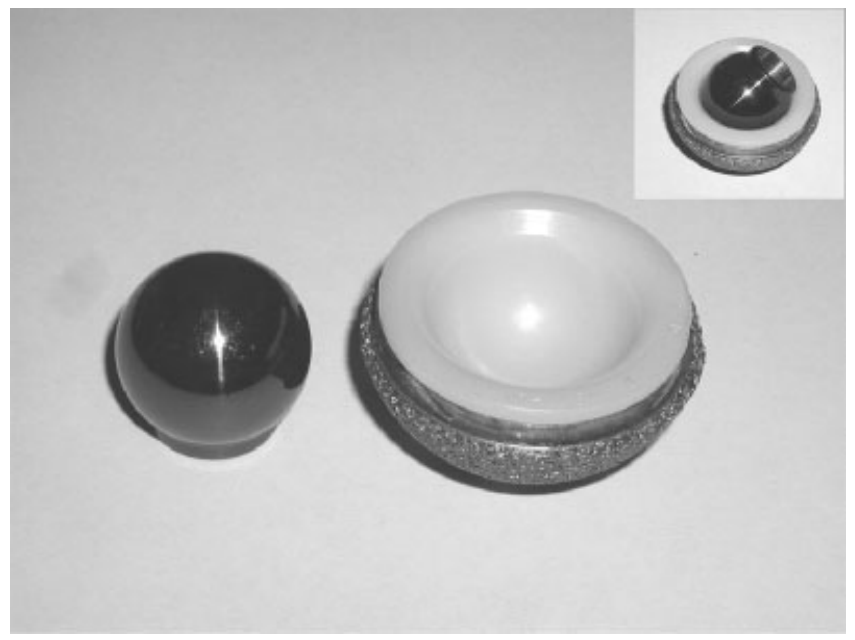

Figure 1. a-C:H coated head and UHMWPE acetabular surface of a hip joint by radio frequency plasma-assisted chemical vapor deposition.

should also have good adhesion on the substrate especially in human body fluid. Several attempts were done to study the wear and corrosion of the biomaterials in artificial joint fluids like bovine serum, saline water, Ringer solution, or phospholipids. ${ }^{52,53}$

There have been many studies from the last decade to coat orthopedic materials with hard coatings to decrease the wear rate for better prosthetic application. ${ }^{54,55}$ DLC, with its excellent tribological properties, has emerged as a potential material to reduce the wear rate and corrosion. Figure 1 shows an example of a-C:H coated femoral head of Ti-6Al-4V alloy prepared by r.f.-PECVD method. The counterface of the DLC-coated femoral head is mostly a polymer acetabular cup made of ultrahigh molecular weight polyethylene (UHMWPE). In 1993, an attempt was made to study the adherence of a-C:H or nitrogen incorporated a-C films on joint prosthesis materials like metals, ceramics, and polymers by means of scratch hardness testing. ${ }^{56}$ Some extensive studies were carried out on wear reduction effects of Co-Cr, alumina, and a-C: $\mathrm{H}$ coated $\mathrm{Co}-\mathrm{Cr}$ with metal adhesion layer against UHMWPE by a special knee wear simulator. ${ }^{57}$ It was observed that the a-C:H coating suppressed the wear of UHMWPE. A comparative tribological tests using ball-on-disk (BOD) and pin-on-disk (POD) configuration were also made in dry condition to investigate the wear of different materials used in hip joint prostheses against UHMWPE. ${ }^{58}$ They compared the wear rate of stainless steel, titanium, alumina, zirconium oxide, a-C:H coated stainless steel, and a-C:H coated titanium, which revealed the superiority of the a-C:H coatings. A hip simulator was used by Tiainen ${ }^{59}$ to study the mechanical properties of tetrahedral amorphous carbon (ta-C) film deposited by filtered pulsed arc discharge method for biomechanical coating. They showed that the wear rate of ta-C coated metal polyethylene joints is $10^{5}-10^{6}$ times smaller than metal polyethylene or metal-metal joints. The corrosion rate is also significantly lowered on exposing the coated substrate to a saline solution equivalent to body fluids in $37^{\circ} \mathrm{C}$ for 2 years. In a more recent tribological study using POD in simulated body fluid, Sheeja et al. ${ }^{60}$ noted that coating both surfaces of UHMWPE and Co-Cr-Mo implants by ta-C film enhanced the life time of the implant to a considerable extent. Dowling et al. ${ }^{61}$ investigated the biocompatibility of a-C:H coated orthopedic implants by in vitro and in vivo studies. The a-C:H film with $\mathrm{sp}^{3}$ content in the range from 40 to $50 \%$ was deposited by acetylene ion beam using a saddle field source. The in vitro tests consisted of human fibroblast adhesion and mutagenicity studies, and the in vivo tests were done by implanting a-C:H-coated stainless steel cylinders in cortical bone and muscular tissue of sheep. Both tests revealed improved biocompatibility of the $\mathrm{a}-\mathrm{C}: \mathrm{H}$ coating. The a-C:H coating on the stainless steel femoral head also minimized wear against UHMWPE as measured by a hip simulator. However, the low wear obtained using a:C-H coating is comparable with that of ceramic femoral heads.

An investigation was done to study the wear of polyethylene acetabular cups against $\mathrm{CoCr}$, alumina, and DLCcoated $\mathrm{CoCr}$ using a hybrid vapor deposition process with a biaxial hip wear simulator using diluted calf serum as the lubricant. ${ }^{53}$ (Detail information of the DLC film is not available in Ref. 53) It was noted that DLC coating did not markedly differ from $\mathrm{CoCr}$ and alumina regarding wear resistance as a counterface for polyethylene. Sheeja et al. ${ }^{62}$ observed that the corrosion resistance and hardness of an orthopedic material like Co-Cr-Mo alloy is significantly increased by ta-C coatings prepared by FCVA technique. However, the wear resistance of the ta-C coated Co-Cr-Mo against UHMWPE measured by a POD tribometer in air, deionized water, and simulated body fluid did not show any significant improvement over $\mathrm{Co}-\mathrm{Cr}-\mathrm{Mo} / \mathrm{UHMWPE}$ sliding pairs. ${ }^{62}$ Dong et al. also used POD tribometer to study the tribological performance of UHMWPE against untreated, a-C coated by unbalanced magnetron sputtering of graphite, nitrogen implanted, thermal oxygen treated (TO) and oxygen diffusion treated Ti-6Al-4V alloy in distilled water environment. ${ }^{63}$ They noticed improvement in tribological behavior with all the surface engineering techniques, but the TO-treated Ti-6Al-4V alloy showed significant less wear than the DLC coating.

Even if some studies revealed that DLC film emerges as a promising material to reduce the wear rates of UHMWPE, the effect of the DLC coating on artificial joints is still in argument. Table I summarized the existing results in terms of the film structure and test method. It is apparent in Table I that some contradiction exists in the test results of the DLC coating. In the case of hydrogenated films, positive results were obtained when tested by POD or BOD type wear rig. However, the positive effect of the coating was not significant in the tests using a hip or knee joint simulator. In contrast, POD or BOD type wear tests of nonhydro- 


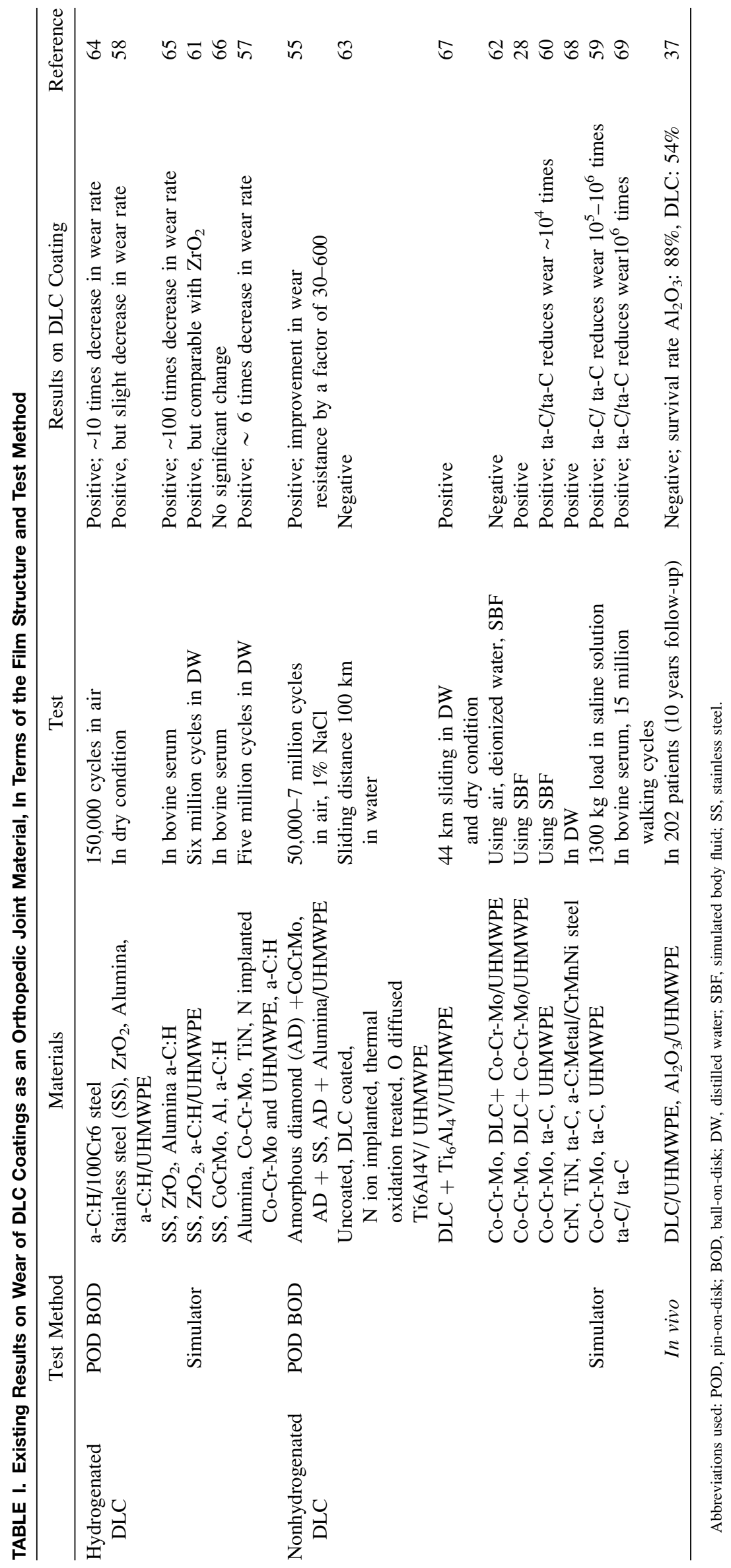


genated film showed both positive and negative results. Only in case of ta-C/ta-C pairs on simulator, is there a significant reduction in wear as compared to conventional polyethylene-metal or metal-metal pairs. Some of these conflicting results may be due to the fact that the lubricant also plays a role in determining the wear of the prosthetic joint material. Ahlroos and Saikko investigated the wear factor of prosthetic joint material in various lubricants and observed that while using synovial fluid or bovine serum as the lubricant, the protein phospholipid affects the wear of UHMWPE and joint materials. ${ }^{70}$ It must also be noted that during hip joint simulator tests, there should be an additive containing proteins to account for the loss of proteins and calcification.

There are also reports of failure of DLC coating in orthopedic implants. For an example, a Swiss company "Implant Design AG" tried to introduce diamond-like nanocomposite (DLN) coated knee joint implant against UHMWPE, but was forced to stop it due to excessive wear and spallation of the joint materials. Furthermore, a clinical test reported that failure rate of the DLC-coated Ti-6Al-4V femoral head is much higher than alumina femoral head. ${ }^{37}$ To understand the failures in the clinical tests, one should also consider the instability of DLC coating in aqueous environments which results in delamination or spallation of the coatings. Numerous surface pits that must follow the spallation of the DLC coating were observed on the coated surface of the failed femoral head. ${ }^{37}$ More in vitro and in vivo research with clinical tests, including failure analysis, is required to confirm the DLC film as a coating material for prosthetic joints.

\section{HEMOCOMPATIBILITY OF DLC FILMS}

When a biomaterial surface comes in contact with blood, it activates various plasma enzyme cascades (the coagulation, fibrinolytic, kinin, and complement system). It is necessary to fabricate biomaterial surfaces that do not activate the plasma enzyme to suppress thrombosis. The interaction of the biomaterial with blood starts with the adsorption of plasma proteins on its surface. The first proteins that are adsorbed on the biomaterial's surface are albumin, fibrinogen, and fibronectin which are then replaced by factors XII and high molecular weight kininogen. All these proteins determine the cellular reaction of a biomaterial. It is the ratio of adsorbed albumin and fibrinogen that determines the hemocompatibility of the biomaterial. As an example, the albumin/fibrinogen ratios of some materials obtained by different research groups were summarized in Ref. 34 Adsorption of albumin retards the adhesion and activation of platelets, while adsorption of fibrinogen promotes platelet adhesion and activation.

The activation of the coagulation mechanism of blood in presence of a biomaterial is estimated by measuring the clotting times, the thrombin time (TT), prothrombin time (PT), and activated partial prothrombin time (APTT). These times maintain the anticoagulation mechanism and regulate the plasma coagulation defects. The TT measures the prevention of final clotting step following the availability of thrombin. The PT estimates the interdiction of the extrinsic coagulation pathway, while the APTT determines the ability of blood to coagulate through the intrinsic coagulation mechanism. The APTT also governs how the biomaterial affects the coagulation time. Moreover, the enzymatic activities which led to clot formation are estimated by PT and APTT measurement. The clotting times are generally measured by a photo-optical method. The hemocompatibility of a biomaterial can also be estimated by measuring the hemolysis ratio. The better hemocompatibility is characterized by a lower hemolysis ratio. The hemolytic effect is characterized by the release of hemoglobin into the plasma from ruptured blood cell.

An early investigation of the hemocompatibility of ta-C film deposited by filtered vacuum arc process was done by measuring the hemolysis ratio and observation of platelet adhesion. ${ }^{23}$ The ta-C films showed improved anticoagulation property compared to low temperature isotropic pyrolytic carbon (LTI carbon). Studies on three events of blood activation such as coagulation, platelet activation, and inflammatory processes have shown that a-C:H coatings by plasma enhanced CVD process have a tendency to prevent activation of platelet and complement convertase in contrast to polymethylmethacrylate, polyethylene, polydimethoxylsiloxane, and medical steel. ${ }^{24}$ The study revealed that the inert nature and smoothness appear to account for the better blood compatibility of the DLC film. Jones et al. ${ }^{25}$ studied the hemocompatibility of a-C:H films synthesized by plasma-enhanced CVD on Ti substrate with interlayers of TiC-TiN. They did not note any significant spreading of platelets on the coated surface. Unlike the interlayers, the a-C:H coating did not show any tendency towards thrombus formation. They also investigated the hemocompatibility of $\mathrm{TiN}, \mathrm{TiC}$, and Ti-incorporated a-C:H film by a reactive sputtering of Ti. They suggested that the better hemocompatibility of $\mathrm{Ti}$ incorporated a-C:H film was due to its hydrophobicity and smooth surface. ${ }^{71}$

Several attempts were made to improve the hemocompatibility of DLC films by incorporating suitable elements into it. Kwok et al. ${ }^{31}$ investigated the blood compatibility of $\mathrm{P}$ doped a-C:H films deposited by plasma immersion ion implantation. They obtained a water contact angle of $16.9^{\circ}$ for their P-doped a-C:H films and observed that the coatings minimized the interaction with plasma proteins. This gives rise to preferential adsorption of albumin, which is a prerequisite for better hemocompatibility. Si incorporation in plasma-enhanced chemical vapor deposited a-C:H was reported to reduce the platelet attachment and improve the human microvascular endothelial cell attachment. ${ }^{30,72}$ Addition of Si lowered the electrical resistivity, work function, and surface energy resulting in improved hemocompatibility. On investigating the antithrombogenicity of fluorinated a-C:H films synthesized by RF plasma-enhanced chemical vapor deposition, it was observed that the incorporation of 
F suppressed the platelet activation and adhesion to a significant extent. ${ }^{73}$ Some studies were also made to modify the surface of DLC by various techniques. ${ }^{34,74}$ All these reports indicated that DLC coatings could be used for hemocompatible devices like stents, guidewires, and heartvalves.

It has been noted that the structure of DLC film played a role on the platelet adhesion of DLC. On investigating the influence of deposition parameters on hemocompatibility of a-C:H films synthesized by plasma immersion ion implantation deposition, Yang et al. ${ }^{22}$ observed that the hemocompatibility improved by depositing the films at lower substrate bias $(-75 \mathrm{~V})$ than at higher substrate bias $(-900 \mathrm{~V})$. On measuring the clotting times TT, PT, and APTT for $\mathrm{a}-\mathrm{C}: \mathrm{H}$ and stainless steel samples, they noted that a-C:H films had a longer APTT than stainless steel. They suggested that the suppression of the contact activation path of the clotting process and reduction of the activation of platelets accounted for the better hemocompatibility of the $\mathrm{a}-\mathrm{C}: \mathrm{H}$ films. On measuring platelet adhesion to uncoated and $\mathrm{a}-\mathrm{C}: \mathrm{H}$ coated $\mathrm{Ti}$ by $13.56 \mathrm{MHz}$ r.f. glow discharge of mixture of methane and hydrogen, Krishnan et al. ${ }^{75}$ observed that the a-C:H coating significantly suppress the I-125 platelet adhesion. Logothetidis et al. ${ }^{76}$ compared the hemocompatibility of magnetron sputtered a-C, a-C:H, and ta-C films. Spectroscopic ellipsometric studies were done in the energy range from 1.5 to $6.5 \mathrm{eV}$ and the albumin/ fibrinogen ratios were derived from the analysis of ellipsometric data. For the a-C:H films, the albumin/fibrinogen ratio was higher for films deposited at higher hydrogen atomic percent in plasma and positive substrate bias. It has also been observed that albumin/fibrinogen ratio was higher for lower refractive index of the carbon films. These results imply that the films with more polymeric component would exhibit better hemocompatibility.

Some attempts were done to investigate the influence of hemocompatibility in terms of the $\mathrm{sp}^{3}$ and $\mathrm{sp}^{2}$ hybrid bond fraction in the DLC films. It was observed that for magnetron sputtered a-C films, the hemocompatibility improved with increasing $\mathrm{sp}^{3}$ fraction. ${ }^{76}$ However, on investigating the hemocompatibility of pulsed vacuum arc deposited ta-C films, it was found out that the hemocompatibility tended to improve with increasing $\mathrm{sp}^{2} / \mathrm{sp}^{3}$ ratio. ${ }^{77}$ For a-C:H films deposited by PIIID, the blood compatibility was enhanced at higher $\mathrm{sp}^{2} / \mathrm{sp}^{3}$ ratio. ${ }^{78}$ Some investigations were performed to observe the dependence of hemocompatibility on the Raman D-band to G-band intensity ratio $\left(I_{\mathrm{D}} / I_{\mathrm{G}}\right)$ of the DLC films. It was noticed that a-C:H coated $\mathrm{TiNi}$ alloy by PIIID showed the better blood compatibility at the minimum value of $I_{\mathrm{D}} / I_{\mathrm{G}} \cdot{ }^{79}$ For silicon incorporated a-C:H films synthesized by PECVD, hemocompatibility increased with decreasing ratio of $I_{\mathrm{D}} / I_{\mathrm{G}} \cdot{ }^{30,74}$

Several studies were reported to discuss the hemocompatibility in terms of the wettability and the surface energy of DLC or element-incorporated DLC films. Kwok et al. ${ }^{31}$ has indicated that higher surface energy of $\mathrm{P}$ doped a-C:H films was associated with weak adsorption of proteins and preferential adsorption of albumin. Huang et al. ${ }^{80}$ also

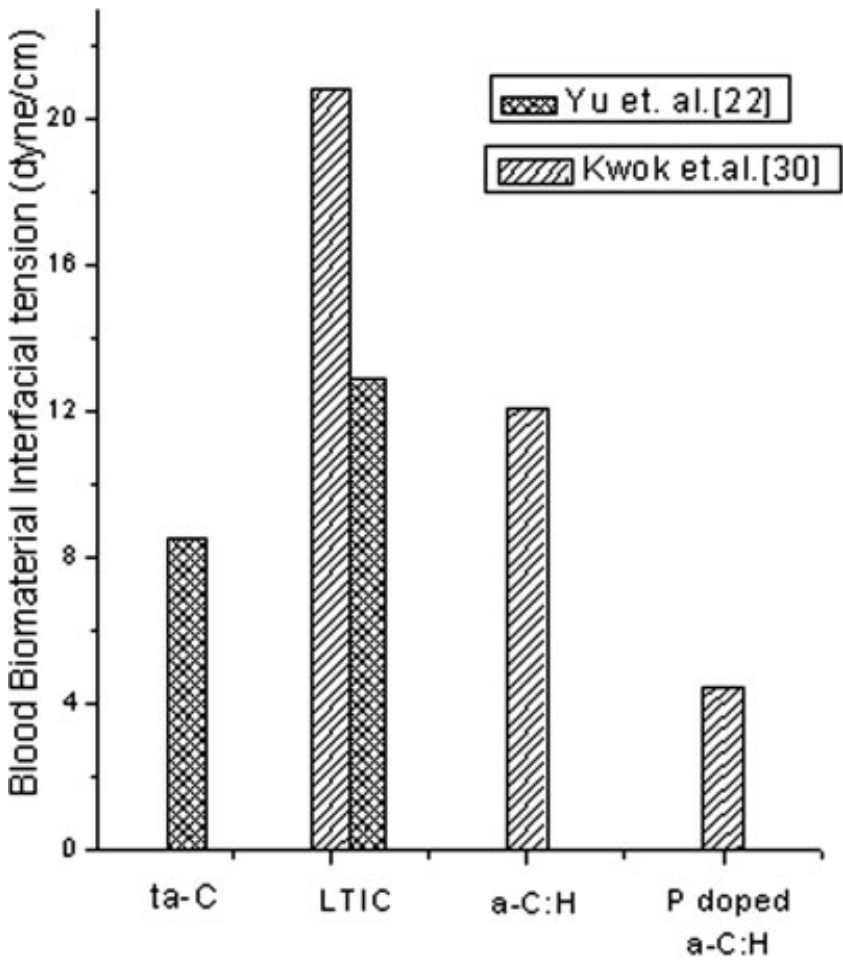

Figure 2. Blood-biomaterial interfacial tensions of different forms of carbon materials estimated by using data in Refs. 23 and 31.

pointed out that hydrophilic surfaces improved blood compatibility. However, while investigating the thrombogenicity of a hydrophilically coated catheter, Leach et al. ${ }^{81}$ has observed that the hydrophilic coatings were equally thrombogenic as the uncoated ones. On the other hand, Jones et al. $^{71}$ reported that hydrophilic surfaces enhanced spreading of platelets and fibrinogen adsorption. They accounted for better hemocompatibility of DLC surfaces due to its low surface energy, hydrophobicity, and smooth surface. Okpalugo et al. $^{72}$ noted that $\mathrm{Si}$ doping in a-C: $\mathrm{H}$ films lowered the surface energy resulting in improved blood compatibility. Saito et al. ${ }^{73}$ also found out that the antithrombogenicity increases with the increase in hydrophobicity of their fluorinated DLC films.

All these investigations revealed that, at present, no consistent relationship was found between the hemocompatibility and the atomic bond structure of carbon or the wettability of the surface. It appears that these parameters are not the sole factor in governing the hemocompatibility. For example, interfacial tension between blood and biomaterials has also been considered to understand the hemocompatibility. It has been observed that the cellular elements of blood maintain an interfacial tension of the order of 23 dyne/cm with blood plasma. It was suggested that the hemocompatibility can be improved when the interfacial tension between blood and biomaterials is in the same order of magnitude. ${ }^{82}$ The blood-biomaterial interfacial tension of different forms of carbon materials obtained by $\mathrm{Yu}$ et al. ${ }^{23}$ and Kwok et al. ${ }^{31}$ are depicted in Figure 2. Another factor to determine the hemocompatibility would 
be the charge transfer from the protein molecule to the biomaterial surface. The adsorption of proteins on biomaterials surfaces is associated with the charge transfer to the biomaterials, and the adsorbed proteins undergo various conformation changes during electron exchange process. It has been observed that fibrinogen has an electronic band gap of $1.8 \mathrm{eV}$. When fibrinogen comes in contact with a material whose Fermi energy level lies below the Fermi energy level of fibrinogen, charge transfer takes place from the valence band of fibrinogen to the material resulting in the adsorption of fibrinogen to form fibrin and finally thrombus. On the other hand, if fibrinogen comes in contact with the materials with higher Fermi energy level than that of fibrinogen, no charge transfer would occur from fibrinogen to the materials, which suppress the oxidation of fibrinogen and thrombus formation. ${ }^{23,80}$ It has thus been suggested that materials with lower electrical resistivity or smaller work function are more hemocompatible. ${ }^{72,83}$ The local surface texture affecting the local blood flow at the surface may also have an influence on the shear strength of the cells and the biobehavior.

One should note that the exact mechanism of selective adsorption of fibrinogen and albumin during blood-biomaterial interaction is not fully understood. A novel design of the hemocompatible surface would originate from the fundamental understanding of the interactions between blood and biomaterials.

\section{DLC-Coated Stents}

A stent is a metal tube that is inserted permanently into an artery. The stent helps open an artery so that blood can flow through it. The cardiovascular implantation of stents is increasing day by day throughout the world. But the application of stents is largely limited by restenosis, occlusion, and stent-associated thrombosis. The main side effect with artery stents lies in its release of metal ions and thrombogenicity. It is thus necessary to coat metallic stents with suitable biomaterial that are hemocompatible, corrosion resistant, and long lasting in human blood environment.

Recent years have witnessed some in vitro and in vivo studies on the coating of stents with DLC films and its effect on platelet activation, thrombogenicity, and metal release. It has been observed that all metals corrode to some degree following implantation. ${ }^{84}$ Release of metals like $\mathrm{Ni}$, $\mathrm{Cr}$, Mo, and Mn has been confirmed from noncoated stents in contact with human plasma for 4 days. ${ }^{4}$ But no such metal release was observed for DLC-coated stents by plasma-induced deposition technique. (Details of the DLC film are not available in Ref. 4) DLC coating also reduced platelet activation and thrombogenicity to a significant extent. There were reports on the implantation of 165 carbon-coated stents in 110 patients for 129 lesions. ${ }^{85}$ Clinical success was noted in all the cases and no stent thrombosis was observed 1 month after implantation. Some comparative studies were made on ta-C-coated, polyurethane-coated, and uncoated stainless steel vascular stents by observing their responses to macrophages. ${ }^{86}$ It was noted that the spreading of macrophages and inflammatory activity was less on ta-C coating than that of polyurethane-coated and uncoated stents.

An attempt was made to study the clinical effect of arterial stenting with turbostratic carbon coating with physical and biologic properties equivalent to pyrolitic carbon. ${ }^{87}$ After implanting the carbon-coated stents in 112 patients for 6 months, no stent failure and thrombosis were noted. The angiographic results of 108 patients revealed a restonosis rate of $11 \%$. A successful implantation of nitinol stents coated with DLC was made in the year 2004 for endovascular treatment of superficial femoral artery occlusive disease. ${ }^{88}$ (Details of the DLC film is not available in Ref. 88.) Primary results of this investigation showed $100 \%$ pretency rate, 12 months after intervention. It is worthwhile to mention here that SMART (shape memory alloy recoverable technology) nitinol self-expanding stents are gaining importance over stainless steel and titanium due to their superior properties of shape memory and superelasticity. Drugeluting stents are also being used to prevent restonosis.

However, another clinical test in the year 2004 reported that a-C:H coating does not provide significant improvements over uncoated stainless steel stents. ${ }^{36}$ A random study of the hemocompatibility of a-C:H coated stainless steel stent was made by comparing it with uncoated stents during treatment of coronary artery disease of 347 patients. ${ }^{36}$ After 6 months implantation, it was observed that the binary restenosis is $31.8 \%$ for a-C:H coated stents and $35.9 \%$ for stainless steel stents, while the major adverse cardiac effect is $30.5 \%$ for a-C:H coated stainless steel stents and $32.7 \%$ for uncoated one.

One should note that the effect of DLC coating would be maintained only when the coating is stable during expansion of the stents. However, plastic deformation in the stent is so localized that the film coated on the plastically deformed region can be damaged. Figure 3 shows the SEM microstructure of a-C:H coated stent after expansion. The a-C:H film was deposited by an ion beam deposition system using benzene as the precursor. The microstructure shows that the plastic deformation is highly localized to the bended region (indicated by an arrow), where severe crack and spallation of the coating occurs. Some attempts were made to incorporate certain elements in DLC and use an interlayer to prevent spallation and cracking of the coating, during high tensile forces of stent expansion. ${ }^{30,89}$ However, minimizing the cracking, spallation and fracture of DLC coating during stent expansion should be the subject of further research. In addition, it is widely known that the adhesion of DLC coating is degraded in an aqueous environment. On immersing the silicon incorporated a-C:H films in biofluids for a month, the interfacial adhesion strength was found to be greatly reduced. ${ }^{30}$ The instability of the DLC coating should also be considered for the applications. 


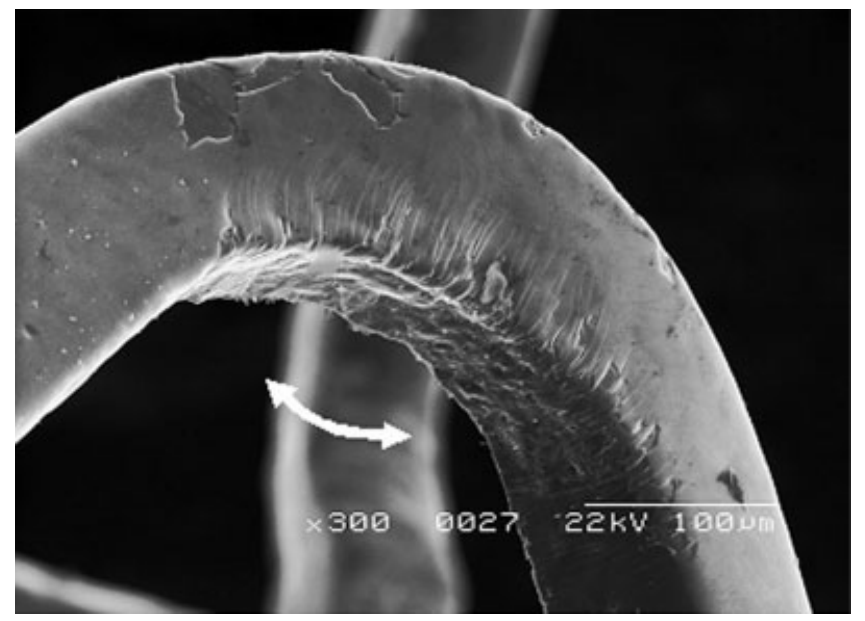

Figure 3. SEM microstructure of a-C:H coated stent after expansion. The film of thickness about $1 \mu \mathrm{m}$ was coated by an ion plating method using benzene. The arrow shows the expansion direction. Array of the cracks perpendicular to the direction of the stress were observed in the tensile side, while spallations of the coating were observed in opposite side where compressive stress was evolved during expansion.

Some companies have come forward to use DLC coatings in medical implants and observe their effects in human body. The company Plasmachem of Germany produces nanocomposite multilayer-coated stents (Figure 4) with DLC as an intermediate layer under the name "Biodiamond stents." 90 They used a DLC coating made by plasmainduced cold deposition technique to coat the inside and outside of their stainless steel 316L stents. The Cardio Carbon Company Ltd. uses DLC-coated Ti implants in mechanical heart valves and heart valve repairs. ${ }^{91}$ Another company, Sorin Biomedica of Italy, utilizes physical vapor deposited carbon to coat their heart valves and stents. ${ }^{92}$ All these applications reveal that DLC coatings have a high prospect for cardiovascular applications. However, longterm stability of the coating should be carefully investigated. In addition, more systematic analysis on the per- formance of DLC-coatings in both in vivo and clinical tests is required.

\section{DLC-Coated Guidewires}

Medical guidewires are used to introduce catheters, stents, and other medical devices inside the human body. A good guidewire should possess inertness, high flexibility, very low coefficient of friction, and short term biocompatibility for effective advancement through the vessel. Normally stainless steel is used as the guide wire material. But for better lubricity and low friction, stainless steel is often coated with polytetrafluoroethylene (PTFE) or silicon overlays. However, these coatings suffer from the side effects of nonuniformity, instability, and poor adhesion with stainless steel resulting in the release of coated materials. It must be noted that the guidewire should not cause any implant trauma or harm the vessel walls, during its insertion along the tortuous path of vessels. DLC, because of its superior lubricate and biocompatible properties, have drawn attention as an alternative to these conventional coatings.

Some studies were made to coat guidewires with DLC and investigate their lubrication, stability, and hemocompatible properties. ${ }^{30,93,94}$ A comparative study was done between plasma-enhanced chemical vapor deposited a-C:H coating on stainless steel guidewires and other existing guidewire coatings. ${ }^{93}$ It was observed that a-C:H coated guidewires exhibited a lower coefficient of friction, better adhesion with stainless steel, higher hardness, and better hemocompatibily than the other coatings like PTFE. To ensure better adhesion with the substrate and stability during guidewire windings, elements like $\mathrm{Si}$ and $F$ have been incorporated in a-C:H film. Use of an a-Si:H interlayer has increased the substrate adhesion significantly, while $\mathrm{Si}$ doping in FCVA deposited ta-C was reported to reduce the film cracking. ${ }^{30}$ Hasebe et al. has studied the lubrication properties of stainless steel guidewires coated with a-C:H and $\mathrm{F}$ incorporated a-C:H, deposited by r.f.-PECVD techniques. $^{94}$ They noted that $\mathrm{a}-\mathrm{C}: \mathrm{H}$ and fluorinated $\mathrm{a}-\mathrm{C}: \mathrm{H}$

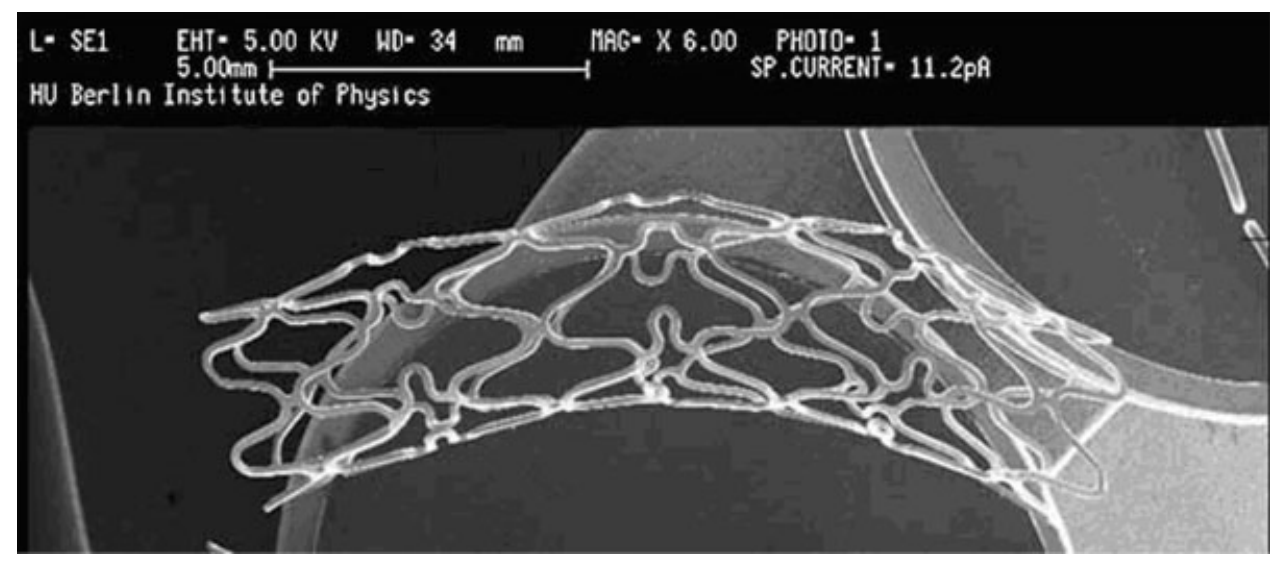

Figure 4. A biodiamond stent of Plasmachem. ${ }^{89}$ Details of the stent are described in the text. 
improved the smoothness, uniformity, and reduced the polishing scars. a-C:H and fluorinated a-C:H were found to improve the lubrication behavior by $30 \%$ compared to uncoated guidewires. Fluorine incorporation in a-C:H also reduced the thrombogenicity significantly. All these results indicate that DLC film containing suitable incorporated elements can be a promising coating layer for guidewires, but care should be taken to prevent its delamination and spallation during guidewire winding.

\section{OTHER BIOMEDICAL APPLICATIONS OF DLC}

Hydrogenated amorphous carbon coatings have been investigated for implants in oral cavity. ${ }^{95,96}$ It was observed that the r.f.-PECVD deposited a-C:H layers showed significant biointegration and resistance to saliva and other oral cavity elements. ${ }^{95}$ Ion beam plated a-C:H films in orthodontic $\mathrm{NiTi}$ archwires prevented the release of $\mathrm{Ni}$ ions in oral saliva. ${ }^{96}$ Some studies were done on the coating of contact lenses by carbon films to improve their opthalmological applications. ${ }^{97,98}$ Ion-assisted carbon films on contact lenses were found to adhere well to the lens materials, enhance stability, provide UV protection, and strengthen the lens life significantly. ${ }^{97}$ The carbon coating also minimized antibacterial activity and inflammatory processes and improved the chemical resistance to sterilization and storage solution of contact lenses. Hydrogenated a-C and carbyne-containing coatings on polymer based medical products, deposited by ion-plasma assisted methods, showed better biocompatibility, chemical inertness, and impart strength to the surface of the medical devices. ${ }^{98}$ Hydrogenated a-C coatings on contact lenses increased the refractive index, thereby reducing the thickness of contact lens. The coatings of thickness in the range 20-200 $\mathrm{nm}$ have good transmission in the visible region but minimizes UV transmission by about $40-$ $50 \%$. Contact lens casings coated with hydrogenated a-C showed significant surface integrity on exposure to saline solution, prevented the formation of microbial contamination and proved to be a safe custody of the contact lenses. A study was carried out on the effects of bioactive surface coatings on neurons. ${ }^{99}$ The investigation revealed that ta- $\mathrm{C}$ film were neurocompatible and could be used as a coating for nanoscale instruments used in the nervous system.

\section{CONCLUSIONS}

A wide variety of studies on biocompatibility of DLC films showed that it is a potential material for biomedical applications. DLC film surface offers favorable condition for the growth of cells like fibroblasts, osteoblasts, and macrophages, without any inflammation and cytotoxicity. DLC coatings in hip and knee joint simulator minimize the wear and corrosion leading to less formation of debris. The release of metal ions from metallic implants is also significantly reduced by DLC coatings. DLC films minimize platelet adhesion and activation, tended to prevent throm- bogenicity, and showed improved hemocompatibility in cardiovascular implants. The biocompatibility of DLC films is also improved by incorporating suitable elements into it.

It must be noted that many previous works report contradictory results about the effect of DLC coating on the improvement of biomedical performance of materials. Two aspects should be carefully addressed. First, DLC coating exhibits a wide range of atomic bond structure and materials properties depending on the deposition condition. Care should thus be taken during interpretation of the contradictory results. An exact characterization of the DLC coating and determination of its surface properties are necessary to correlate the different in-vitro and in-vivo results. Another aspect to be addressed is the adhesion of DLC coating with biomaterials. Because of high residual compressive stress, the coating can spontaneously delaminate if the adhesion is not sufficient, which not only cancels the coating effect but also degrades the biomedical implants by delaminated particles. This problem is significant during its use in orthopedic and cardiovascular application where the medical device faces many tensile and compressive stresses. Furthermore, it was reported that the adhesion is degraded in an aqueous environment mainly due to the interaction between the water molecule and the interface layer. The spallation, delamination, and corrosion of the DLC coatings during its long-term use in medical implants are to be carefully considered for its future biomedical applications. More systematic in vitro and in vivo studies are required to confirm its use in biomedical devices for a commercial basis.

Helpful discussion and invaluable comments of Dr. R. Hauert at EMPA, Switzerland is gratefully acknowledged.

\section{REFERENCES}

1. von Recum AF, editor. Handbook of Biomaterials Evaluation. Philadelphia: Taylor and Francis; 1999.

2. Huang N, Yang P, Leng YX, Chen JY, Sun H, Wang J, Wang GJ, Ding PD, Xi TF, Leng Y. Hemocompatibility of titanium oxide films. Biomaterials 2003;24:2177-2187.

3. Shah AK, Sinha RK, Hickok NJ, Tuan RS. High-resolution morphometric analysis of human osteoblastic cell adhesion on clinically relevant orthopedic alloys. Bone 1999;24:499-506.

4. Gutensohn K, Beythien C, Bau J, Fenner T, Grewe P, Koester R, Padmanaban K, Kuehnl P. In vitro analyses of diamondlike carbon coated stents: Reduction of metal ion release, platelet activation and thrombogenicity. Thromb Res 2000;99: 577-585.

5. Gillespie WL, Frampton CMA, Henderson RJ, Ryan PM. The incidence of cancer following total hip replacement. J Bone Joint Surg Br 1988;70:539-542.

6. Cui FZ, Luo ZS. Biomaterials modification by ion beam processing. Surf Coat Technol 1999;112:278-285.

7. Li DJ, Cui FZ, Gu HQ. Studies of diamond-like carbon films coated on PMMA by ion beam assisted deposition. Appl Surf Sci 1999;137:30-37.

8. Sánchez-López JC, Donnet C, Fontaine J, Belin M, Grill A, Patel V, Jahnes C. Diamond-like carbon prepared by high density plasma. Diamond Relat Mater 2000;9:638-642. 
9. Lee CS, Lee KR, Eun KY, Yoon KH, Han JH. Structure and properties of $\mathrm{Si}$ incorporated tetrahedral amorphous carbon films prepared by hybrid filtered vacuum arc process. Diamond Relat Mater 2002;11:198-203.

10. Zou YS, Wang W, Song GH, Du H, Gong J, Huang RF, Wen LS. Influence of the gas atmosphere on the microstructure and mechanical properties of diamond-like carbon films by arc ion plating. Mater Lett 2004;58:3271-3275.

11. Thorwarth G, Hammerl C, Kuhn M, Assmann W, Schey B, Stritzker B. Investigation of DLC synthesized by plasma immersion ion implantation and deposition. Surf Coat Technol 2005; 193:206-212.

12. Sánchez NA, Rincón C, Zambrano G, Galindo H, Prieto P. Characterization of diamond-like carbon (DLC) thin films prepared by r.f. magnetron sputtering. Thin Solid Films 2000; 373:247-250.

13. He X, Li W, Li H. Bonding structure and tribological properties of DLC films synthesized by dual ion beam sputtering. Vacuum 1994;45:977-980.

14. Shim KS, Kim SM, Bae SH, Lee SY, Jung HS, Park HH. Fabrication and characterization of diamond-like carbon thin films by pulsed laser deposition. Appl Surf Sci 2000;154/155: 482-484.

15. Hofsäss H, Binder H, Klumpp T, Recknagel E. Doping and growth of diamond-like carbon films by ion beam deposition. Diamond Relat Mater 1994;3:137-142.

16. DeBakey ME. Development of mechanical heart devices. Ann Thorac Surg 2005;79:S2228-S2231.

17. Thomson LA, Law FC, Rushton N, Franks J. Biocompatibility of diamond-like carbon coating. Biomaterials 1991;12:37-40.

18. Evans AC, Franks J, Revell PJ. Diamond-like carbon applied to bioengineering materials. Surf Coat Technol 1991;47:662667.

19. Mitura E, Mitura S, Niedzielski P, Has Z, Wolowiec R, Jakubowski A, Szmidt J, Sokolowska A, Louda P, Marciniak J, Koczy B. Diamond-like carbon coatings for biomedical applications. Diamond Relat Mater 1994;3:896-898.

20. Butter R, Allen M, Chandra L, Lettington AH, Rushton N. In vitro studies of DLC coatings with silicon intermediate layer. Diamond Relat Mater 1995;4:857-861.

21. Du C, Su XW, Cui FZ, Zhu XD. Morphological behaviour of osteoblasts on diamond-like carbon coating and amorphous CN film in organ culture. Biomaterials 1998;19:651-658.

22. Yang P, Kwok SCH, Chu PK, Leng YX, Chen JY, Wang J, Huang N. Haemocompatibility of hydrogenated amorphous carbon $(\mathrm{a}-\mathrm{C}: \mathrm{H})$ films synthesized by plasma immersion ion implantation-deposition. Nucl Instrum Methods Phys Res Sect B 2003;206:721-725.

23. Yu LJ, Wang X, Wang XH, Liu XH. Haemocompatibility of tetrahedral amorphous carbon films. Surf Coat Technol 2000; 128/129:484-488.

24. Nurdin N, Francois P, Moret M, Unal K, Krumeich J, Aronsson BO, Descounts P. Hemocompatible diamond-like carbon (DLC) surfaces. Eur Cells Mater 2003;5:17-28.

25. Jones MI, McColl IR, Grant DM, Parker KG, Parker TL. Haemocompatibility of DLC and TiC-TiN interlayers on titanium. Diamond Relat Mater 1999;8:457-462.

26. Linder S, Pinkowski W, Aepfelbacher M. Adhesion, cytoskeletal architecture and activation status of primary human macrophages on a diamond-like carbon coated surface. Biomaterials 2002;23:767-773.

27. Mohanty M, Anilkumar TV, Mohanan PV, Muraleedharan CV, Bhuvaneshwar GS, Derangere F, Sampeur Y, Suryanarayanan R. Long term tissue response to titanium coated with diamond like carbon. Biomol Eng 2002;19:125-128.

28. Sheeja D, Tay BK, Nung LN. Feasibility of diamond-like carbon coatings for orthopaedic applications. Diamond Relat Mater 2004;13:184-190.
29. Kim HG, Ahn SH, Kim JG, Park SJ, Lee KR. Electrochemical behavior of diamond-like carbon films for biomedical applications. Thin Solid Films 2005;475:291-297.

30. Maguire PD, McLaughlin JA, Okpalugo TIT, Lemoine P, Papakonstantinou P, McAdams ET, Needham M, Ogwu AA, Ball M, Abbas GA. Mechanical stability, corrosion performance and bioresponse of amorphous diamond-like carbon for medical stents and guidewires. Diamond Relat Mater 2005;14: $1277-1288$.

31. Kwok SCH, Wang J, Chu PK. Surface energy, wettability, and blood compatibility phosphorus doped diamond-like carbon films. Diamond Relat Mater 2005;14:78-85.

32. Schroeder A, Francz G, Bruinink A, Hauert R, Mayer J, Wintermantel E. Titanium containing amorphous hydrogenated carbon films (a-C: H/Ti): Surface analysis and evaluation of cellular reactions using bone marrow cell cultures in vitro. Biomaterials 2000;21:449-456.

33. Grill A. Diamond-like carbon coatings as biocompatible materials-An overview. Diamond Relat Mater 2003;12:166170.

34. Hauert R. A review of modified DLC coatings for biological applications. Diamond Relat Mater 2003;12:583-589.

35. Dorner-Reisel A, Schürer C, Nischan C, Seidel O, Müller E. Diamond-like carbon: Alteration of the biological acceptance due to Ca-O incorporation. Thin Solid Films 2002;420 421:263-268.

36. Airoldi F, Colombo A, Tavano D, Stankovic G, Klugmann S, Paolillo V, Bonizzoni E, Briguori C, Carlino M, Montorfano M. Comparison of diamond like carbon coated stents versus uncoated stainless steel stents in coronary artery disease. Am J Cardiol 2004;93:474-477.

37. Taeger G, Podleska LE, Schmidt B, Ziegler M, Nast-Kolb D. Comparison of diamond-like carbon and alumina oxide articulating with polyethylene in total hip anthroplasty. Mat-wiss u Werkstofftech 2003;34:1094-1100.

38. Lee KR, Eun KY. Diamond-like carbon film. Bull Korean Inst Met Mater 1993;6:345-361.

39. Cui FZ, Li DJ. A review of investigations on biocompatibility of diamond-like carbon and carbon nitride films. Surf Coat Technol 2000;131:481-487.

40. Dearnaley G, Arps JH. Biomedical applications of diamondlike carbon (DLC) coatings: A review. Surf Coat Technol 2005; 200:2518-2524.

41. Narayan RJ. Nanostructured diamondlike carbon thin films for medical applications. Mater Sci Eng C 2005;25:405-416.

42. Culp LA, Murray BA, Rollins BJ. Fibronectin and proteoglycans as determinants of cell substratum adhesion. J Supramol Struct 1979;11:401-427.

43. McColl IR, Grant DM, Green SM, Wood JV, Parker TL, Parker K, Goruppa AA, Braithwaite NStJ. Low temperature plasma-assisted chemical vapour deposition of amorphous carbon films for biomedical-polymeric substrates. Diamond Relat Mater 1993;3:83-87.

44. Hauert R, Müller U, Francz G, Birchler F, Schroeder A, Mayer J, Wintermantel E. Surface analysis and bioreactions of $\mathrm{F}$ and Si containing a-C:H. Thin Solid Films 1997;308/ 309:191-194.

45. Singh A, Ehteshami G, Massia S, He J, Storer RG, Raupp G. Glial cell and fibroblast cytotoxicity study on plasma-deposited diamond-like carbon coatings Biomaterials 2003;24: 5083-5089.

46. Francz G, Schroeder A, Hauert R. Surface analysis and bioreactions of Ti- and V-containing a-C: H. Surf Interface Anal 1999;28:3-7.

47. Allen M, Myer B, Rushton N. In vitro and in vivo investigations into the biocompatibility of diamond-like carbon (DLC) coatings for orthopedic applications. J Biomed Mater Res B 2001;58:319-328. 
48. Guglielmotti MB, Renou S, Cabrini RL. A histomorphometric study of tissue interface by laminar implant test in rats. Int J Oral Maxillofac Implants 1999;14:565-570.

49. Zolynski K, Witkowski P, Kaluzny A, Has Z, Niedzielski P, Mitura S. Implants with hard carbon layers for application in pseudoarthrosis femoris sin. ostitis post fracturam apertam olim factam. J Chem Vapor Depos 1996;4:232-239.

50. Hynes RO, Yamada KM. Fibronectins: Multifunctional modular glycoproteins. J Cell Biol 1982;95:369-377.

51. Yokota T, Terai T, Kobayashi T, Iwaki M. Cell adhesion to nitrogen-doped DLCS fabricated by plasma-based ion implantation and deposition method. Nucl Instrum Methods Phys Res Sect B 2006;242:48-50.

52. Saikko V, Ahlroos T. Phospholipids as boundary lubricants in wear tests of prosthetic joint materials. Wear 1997;207:86-91.

53. Saikko V, Ahlroos T, Calonius O, Keränen J. Wear simulation of total hip prostheses with polyethylene against $\mathrm{CoCr}$, alumina and diamond-like carbon. Biomaterials 2001;22: 1507-1514.

54. Wimmer MA, Loos J, Nassutt R, Heitkemper M, Fischer A. The acting wear mechanisms on metal-on-metal hip joint bearings: In vitro results. Wear 2001;250:129-139.

55. Lappalainen R, Heinonen H, Anttila A, Santavirta S. Some relevant issues related to the use of amorphous diamond coatings for medical applications. Diamond Relat Mater 1998;7: 482-485.

56. Lankford J, Blanchard CR, Agrawal CM, Micallef DM, Dearnaley G, McCabe AR. Adherence of diamondlike carbon coatings on total joint substrate materials. Nucl Instrum Methods Phys Res Sect B 1993;80/81:1441-1445.

57. Oñate JI, Comin M, Braceras I, Garcia A, Viviente JL, Brizuela M, Garagorri N, Peris JL, Alava JI. Wear reduction effect on ultra-high-molecular-weight polyethylene by application of hard coatings and ion implantation on cobalt chromium alloy, as measured in a knee wear simulation machine. Surf Coat Technol 2001;142-144:1056-1062.

58. Platon F, Fournier P, Rouxel S. Tribological behaviour of DLC coatings compared to different materials used in hip joint prostheses. Wear 2001;250:227-236.

59. Tiainen VM. Amorphous carbon as a bio-mechanical coating-Mechanical properties and biological applications. Diamond Relat Mater 2001;10:153-160.

60. Sheeja D, Tay BK, Nung LN. Tribological characterization of surface modified UHMWPE against DLC-coated Co-Cr-Mo. Surf Coat Technol 2005;190:231-237.

61. Dowling DP, Kola PV, Donnelly K, Kelly TC, Brumitt K, Lloyd L, Eloy R, Therin M, Weill N. Evaluation of diamondlike carbon-coated orthopaedic implants. Diamond Relat Mater 1997;6:390-393.

62. Sheeja D, Tay BK, Lau SP, Nung LN. Tribological characterisation of diamond-like carbon coatings on Co-Cr-Mo alloy for orthopaedic applications. Surf Coat Technol 2001;146/ 147:410-416.

63. Dong H, Shi W, Bell T. Potential of improving tribological performance of UHMWPE by engineering the $\mathrm{Ti}_{6} \mathrm{Al}_{4} \mathrm{~V}$ counterfaces. Wear 1999;225-229:146-153.

64. Hauert R, Knoblauch-Meyer L, Francz G, Schroeder A, Wintermantel E. Tailored a-C:H coatings by nanostructuring and alloying. Surf Coat Technol 1999;120/121:291-296.

65. Shi B, Ajayi OO, Fenske G, Erdemir A, Liang H. Tribological performance of some alternative bearing materials for artificial joints. Wear 2003;255:1015-1021.

66. Affatato S, Frigo M, Toni A. An in vitro investigation of diamond-like carbon as a femoral head coating. J Biomed Mater Res B 2000;53:221-226.

67. Xu T, Pruitt L. Diamond-like carbon coatings for orthopaedic applications: An evaluation of tribological performance. J Mater Sci Mater Med 1999;10:83-90.
68. Reuter S, Weßkamp B, Büscher R, Fischer A, Barden B, Löer F, Buck V. Correlation of structural properties of commercial DLC-coatings to their tribological performance in biomedical applications. Wear 2006;261:419-425.

69. Lappalainen R, Selenius M, Anttila A, Konttinen YT, Santavirta SS. Reduction of wear in total hip replacement prostheses by amorphous diamond coatings. J Biomed Mater Res B 2003;66:410-413.

70. Ahlroos T, Saikko V. Wear of prosthetic joint materials in various lubricants. Wear 1997;211:113-119.

71. Jones MI, McColl IR, Grant DM, Parker KG, Parker TL. Protein adsorption and platelet attachment and activation, on TiN, TiC, and DLC coatings on titanium for cardiovascular applications. J Biomed Mater Res 2000;52:413-421.

72. Okpalugo TIT, Ogwu AA, Maguire PD, McLaughlin JAD. Platelet adhesion on silicon modified hydrogenated amorphous carbon films. Biomaterials 2004;25:239-245.

73. Saito $T$, Hasebe $T$, Yohena S, Matsuoka Y, Kamijo A, Takahashi K, Suzuki T. Antithrombogenicity of fluorinated diamond-like carbon films. Diamond Relat Mater 2005;14: $1116-1119$.

74. Huang N, Yang P, Leng YX, Wang J, Sun H, Chen JY, Wan GJ. Surface modification of biomaterials by plasma immersion ion implantation. Surf Coat Technol 2004;186: 218-226.

75. Krishnan LK, Varghese N, Muraleedharan CV, Bhuvaneshwar GS, Derangère F, Sampeur Y, Suryanarayanan R. Quantitation of platelet adhesion to $\mathrm{Ti}$ and DLC-coated $\mathrm{Ti}$ in vitro using ${ }^{125}$ I-labeled platelets. Biomol Eng 2002;19:251-253.

76. Logothetidis S, Gioti M, Lousinian S, Fotiadou S. Haemocompatibility studies on carbon-based thin films by ellipsometry. Thin Solid Films 2005;482:126-132.

77. Leng YX, Chen JY, Yang P, Sun H, Wan GJ, Huang N. Mechanical properties and platelet adhesion behavior of diamond-like carbon films synthesized by pulsed vacuum arc plasma deposition. Surf Sci 2003;531:177-184.

78. Chen JY, Wang LP, Fu KY, Huang N, Leng Y, Leng YX, Yang P, Wang J, Wan GJ, Sun H. Blood compatibility and $\mathrm{sp}^{3} / \mathrm{sp}^{2}$ contents of diamond-like carbon (DLC) synthesized by plasma immersion ion implantation-deposition. Surf Coat Technol 2002;156:289-294.

79. Cheng Y, Zheng YF. The corrosion behavior and hemocompatibility of TiNi alloys coated with DLC by plasma based ion implantation. Surf Coat Technol 2006;200:45434548 .

80. Huang N, Yang P, Leng YX, Wang J, Chen JY, Sun H, Wan GJ, Zhao AS, Ding PD. Surface modification for controlling the blood-materials interface. In: The Sixth Asia Symposium on Biomaterials, July 20-23; 2004, Chengdu, China.

81. Leach KR, Kurisu Y, Carlson JE, Repa I, Epstein DH, Urness M, Sahatjian R, Hunter DW, Casteneda-Zuniga WR, Amplatz K. Thrombogenicity of hydrophilically coated guide wires and catheters. Radiology 1990;175:675-677.

82. Ruckensten E, Gourisanker SV. A surface energetic criterion of blood compatibility of foreign surfaces. J Colloid Interface Sci 1984;101:436-451.

83. Bruck SD. The role of electrical conduction of macromolecules in certain biomedical problems. Polymer 1975;16:2530.

84. Ferguson A, Laing P, Hodge E. Ionization of metal implants in living tissues. J Bone Joint Surg A 1960;42:77-90.

85. Bartorelli AL, Trabattoni D, Montorsi P. Aspirin alone antiplatelet regimen after intracoronary placement of the Carbostent: The ANTARES study. Catheter Cardiovasc Interv 2002; 55:150-156.

86. Ball M, O’Brien A, Dolan F, Abbas G, McLaughlin JA. Macrophage responses to vascular stent coatings. J Biomed Mater Res A 2004;70:380-390. 
87. Antoniucci D, Bartorelli A, Valenti R, Montorsi P, Santoro GM, Fabbiocchi F, Bolognese L, Loaldi A, Trapani M, Trabattoni D, Moschi G, Galli S. Clinical and angiographic outcome after coronary arterial stenting with the carbostent. Am J Cardiol 2000;85:821-825.

88. Schaefer O, Lohrmann C, Winterer J, Kotter E, Langer M. Endovascular treatment of superficial femoral artery occlusive disease with stents coated with diamond-like carbon. Clin Radiol 2004;59:1128-1131.

89. Choi HW, Lee KR, Wang R, Oh KH. Fracture behavior of diamond-like carbon films on stainless steel under a microtensile test condition. Diamond Relat Mater 2006;15:38-43.

90. http://www.plasmachem.com.

91. http://members.evansville.net/ict/valve-angelini.htm.

92. http://www.sorincardio.com.

93. McLaughlin JA, Meenan B, Maguire P, Jamieson N. Properties of diamond like carbon thin film coatings on stainless steel medical guidewires. Diamond Relat Mater 1996;5:486491.

94. Hasebe T, Matsuoka Y, Kodama H, Saito T, Yohena S, Kamijo A, Shiraga N, Higuchi M, Kuribayashi S, Takahashi
K, Suzuki T. Lubrication performance of diamond-like carbon and fluorinated diamond-like carbon coatings for intravascular guidewires. Diamond Relat Mater 2006;15:129-132.

95. Olborska A, Swider M, Wolowiec R, Niedzielski P, Rylski A, Mitura S. Diamond-like carbon coatings for biomedical applications. Diamond Relat Mater 1994;3:899-901.

96. Kobayashi S, Ohgoe Y, Ozeki K, Sato K, Sumiya T, Hirakuri KK, Aoki H. Diamond-like carbon coatings on orthodontic archwires. Diamond Relat Mater 2005;14:1094-1097.

97. Sleptsov VV, Elinson VM, Simakina NV, Laymin AN, Tsygankov IV, Kivaev AA, Musina AD. Ophthalmological application of contact lenses modified by means of ionassisted carbon films. Diamond Relat Mater 1996;5:483-485.

98. Elinson VM, Sleptsov VV, Laymin AN, Potraysay VV, Kostuychenko LN, Moussina AD. Barrier properties of carbon films deposited on polymer-based devices in aggressive environments. Diamond Relat Mater 1999;8:2103-2109.

99. Ignatius MJ, Sawhney N, Gupta A, Thibadeau BM, Monteiro OR, Brown IG. Bioactive surface coatings for nanoscale instruments: Effects on CNS neurons. J Biomed Mater Res 1998;40:264-274. 